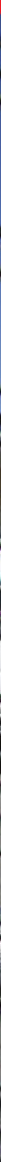

\title{
SCHOOL OF NUKES
}

How do nuclear inspectors know when all is not as they are told? Geoff Brumfiel joins some inspectors-in-training as they learn the ropes at the Los Alamos National Laboratory.

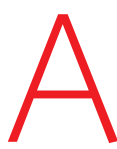

thalf-past eight in the morning, the New Mexico sun already hot on our necks, we gather outside what could be the entrance of a high-security prison. Past the guard post and fence lies a tan, windowless building that covers about a city block. Gill-like vents along the building's side give it the look of a leviathan beached unnaturally in the high desert.

This is the Chemistry and Metallurgy Research building at Los Alamos National Laboratory, the United States' oldest nuclearweapons laboratory. The 51,000-square-metre building is the weapons programme's main centre for the study of nuclear material.

But for the next two weeks the building will serve another purpose. It will be a training base for a fresh crop of nuclear inspectors for the International Atomic Energy Agency (IAEA). The IAEA is the United Nations' body charged with ensuring that the world's civilian nuclear facilities are being used for peaceful purposes, and it relies on about 250 highly trained individuals to do the job. The seventeen inspectors waiting at the gate are here as part of the agency's on-going training programme, honing the skills needed to stop the spread of nuclear weapons. The inspectors are "the eyes and ears on the ground", says David Albright, head of the Institute for Science and International Security, a non-proliferation group based in Washington DC. "And they're quite effective."

When I was younger, I entertained the thought that I, too, might want to be a nuclear inspector. I imagined travelling the world with a diplomatic passport, turning up unexpectedly at secretive facilities and matching wits with local despots. So when the IAEA offered to let me tag along on the first few days of this August's course I jumped at the chance.

My two days as a student there taught me that the reality is at once more tedious and more demanding than my Ian Fleming fantasy would have led me to believe. Inspectors are part scientist, part detective and part diplomat, says Jean Maurice Andre Crete, who heads the IAEA's training programme at their headquarters in Vienna, Austria. They also need to be part accountant, keeping meticulous logs of reactor operations, waste-pool inventories and research-material stocks. And they must be personable enough to win the trust of local plant managers. They must be Jacks and Jills of all trades.

To reach that goal, inspectors undergo a gruelling three-month induction and take continuing education courses in subjects as diverse as international law, psychology, satellite imagery analysis and environmental sampling throughout their career. But at the heart of it all is the need to be able to verify whether the canister in front of them contains the radioactive material that its custodians claim is inside. And that's why they train at Los Alamos. In the belly of the metallurgy behemoth, they have an opportunity to get to grips with pure weapon's-grade uranium and plutonium.

\section{Blending in}

If it wasn't for the fact that we're shuffling about in front of one of the world's most fortified scientific laboratories, we'd be an unas-

"The inspectors
are the eyes
and ears on the
ground."
- David Albright
suming group. We come from 11 countries, spanning the globe from Argentina to Indonesia. All but two of us are men, and we're mostly middle-aged and dressed in polo shirts, khakis and tennis shoes.

Most are nuclear engineers, but a few are scientists. One of the younger inspectors, called Giuseppe, is an Italian radiochemist who was working at a national research institute near Milan before joining the agency last year. Another, named Valeriy, has a $\mathrm{PhD}$ in particle physics, although he has worked in the field of uranium enrichment for 
decades, first in the Soviet Union and later in the Russian Federation.

Security is tight, so much so that we have to keep in our escort's line of sight at all times. We cross an immaculate front lawn distinctly out of place between the razor-wire and the formidable walls. A lone cooler sits on a picnic table. "That's the good thing about working behind the fence," jokes Peter Santi, one of our instructors. "Nobody's going to steal your lunch."

We wind down the staircase

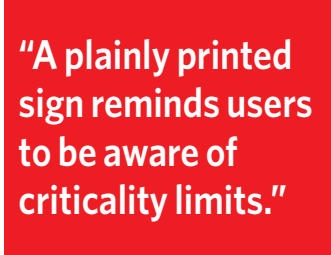

gently into a set of 18 or so cylindrical detectors placed around the foam. When the helium-3 atoms inside these detectors are struck by a neutron, they release a cascade of charged particles that goes on to be picked up by a high-voltage wire at the centre of each detector.

It's a low-tech, cheap and durable way of counting neutrons. Nothing fancy, nothing too complicated; reliable and portable. "The techniques aren't that new, and they're not that challenging," Santi says. "The challenge is to understand how to our basement lab. Blast barriers line the hallways to protect heavily armed guards if attackers try and storm the building. But in contrast to the imposing exterior, the room in which the inspectors will spend the next two weeks is more like a college physics laboratory than a secure nuclear facility. The main room has eight tidy lab stations, each with its own instruments and worksheets. Friendly looking instructors chat casually over coffee. Only two things hint that something more dangerous is at play: a line of wall safes that hold canisters of high-purity uranium-235 and plutonium-239, and a plainly printed sign reminding users to be aware of 'criticality limits' - that is, the maximum amount of material that can be brought together without triggering a nuclear incident.

\section{Indirect comparisons}

After introductions, David Bracken, head of training at Los Alamos, gives a brief overview of the next two weeks. The inspectors will learn about what is known in the business as a non-destructive assay, or NDA. An NDA is a suite of measurements that allows inspectors to determine both the quantity and composition of a material without ever sampling it directly. Done right, it can verify a country's stocks of nuclear material quickly and cheaply. "It's the foundation of safeguarding," Bracken tells us.

An NDA basically comes down to measuring two types of radiation $-\gamma$-rays and neutrons. The $\gamma$-rays, energetic photons emitted during nuclear decays, give a distinctive energy spectrum that is a fingerprint of a material's elemental composition. The neutrons provide a measurement of the quantity of material involved.

I haven't studied physics in nearly a decade, but I can follow the morning's lecture on neutron measurements without difficulty. It's a fairly simple technique: the material is placed at the centre of a doughnut of polyethylene foam. The polyethylene slows down the neutrons sputtering out of the sample so that they drift they fit into the real world."

That afternoon, Santi's warning starts to make sense. A multitude of factors can affect the measurements. The distance of the detectors from the source; the thickness of the foam; the shape of the sample; the quality of calibration in the field: all these can trick an inspector into thinking that there is less, or more, or a different kind of material than is actually present.

Measuring $\gamma$-rays is also quite simple - we are given detectors just like the ones I used in my undergraduate lab work. But in the real world, shielding can block crucial features of a material's spectrum, and a dizzying array of common impurities, such as caesium and cobalt, can confound even the simplest detection. This is exactly why the inspectors are brought to Los Alamos, Bracken tells me. Only in a facility such as the metallurgy centre will the inspectors get the chance to work directly with realistically large quantities of weapon's-grade materials. "The way we teach here isn't just to push a button,"

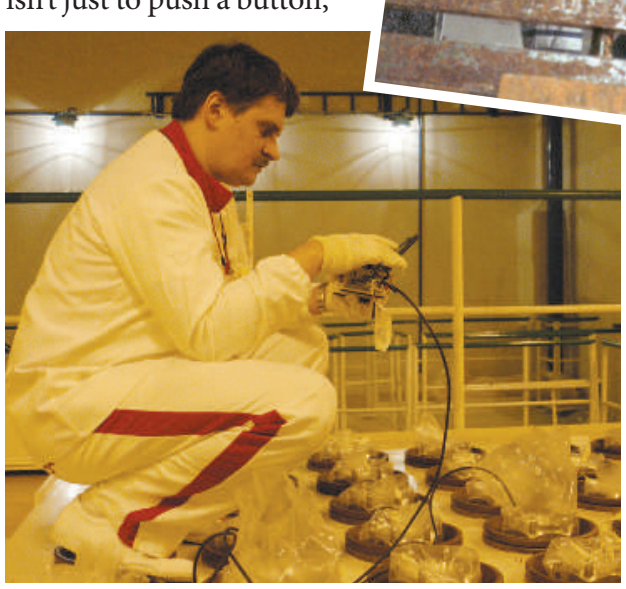

James Bond's world (top) is a long way from that of a nuclear inspector.
Bracken says. "We try to teach the physics, teach them how to think."

Over lunch with Giuseppe, I learn that taking these measurements in the field is tougher still, because there's very little support. Only in the most confrontational cases, such as Iran and North Korea, do inspectors work in teams of the sort that appear on television. On visits to places such as Germany or Mexico they travel alone.

\section{Field work}

In nuclear power plants, especially, the inspectors must also work quickly. Commercial reactors are generally checked during refuelling outages, which companies try to complete as quickly as possible to maintain their profits. "You have just a few minutes," says Giuseppe. "And you have ten people standing behind you, talking in a language you don't understand."

Sometimes, the staff at a facility will try to restrict the inspectors' access, not necessarily to hide anything but simply to try and speed the inspection along. "If you're not prepared, people can sometimes prevent you from doing what you're trying to do," he says. "You have to be very sure about your rights."

Indeed, the rights of a nuclear inspector have changed radically over the past decade, says Crete. Inspectors used to have no

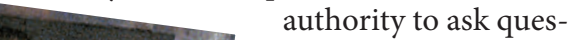
tions or search for additional, undeclared stocks. But all that changed in 1997, with the amendment of the Nuclear Non-proliferation Treaty - the international agreement under which the IAEA operates. "Now we are allowed to ask some questions," he says. They also have the right to check for hidden stock.

After my two days, I head back down from the mesa. I can see the attractions of the world my sort-of classmates are learning to negotiate. "It's a very dynamic kind of life," says the 37-year-old Giuseppe, happy with his career shift, with three months of every year on the road and a bag packed at all times for unexpected trips. "You don't know exactly what to expect," he says. But as someone who's both indiscreet and not much of a detail person, I wouldn't be the man for it. Better for me and non-proliferation both that I gave up the fantasy and took up the notepad.

Geoff Brumfiel writes for Nature from London. 